\title{
A rare association between Fabry's disease and granulomatosis with polyangiitis: a potential pathogenic link
}

\author{
Hironari Hanaoka ${ }^{1 *}$, Akinori Hashiguchi ${ }^{2}$, Konosuke Konishi ${ }^{3}$, Tomohiro Ishii ${ }^{4}$ and Masataka Kuwana ${ }^{1}$
}

\begin{abstract}
Background: Fabry's disease is a rare X-linked, hereditary lysosomal storage disease caused by a deficiency of the enzyme a-galactosidase A. Granulomatosis with polyangiitis is characterized by the involvement of the respiratory tract and kidneys. Here, we report the first case of the coexistence of these diseases.

Case presentation: We describe a 29-year-old man suffering from fever with maxillary sinusitis, multiple lung nodules, and proteinuria. He was diagnosed with Fabry's disease accompanying granulomatosis with polyangiitis on the basis of the low activity of peripheral leukocyte a-galactosidase A and pathological findings in the lung and kidney. Glucocorticoid and cyclophosphamide were administered, followed by enzyme replacement therapy. Progression to end-stage renal disease has not been observed for 6 years until the time of drafting this manuscript.

Conclusion: Because both Fabry's disease and granulomatosis with polyangiitis or crescentic glomerulonephritis are rare diseases, their concurrence in this and related cases suggests there may be a pathogenic link between these two conditions. Fabry's disease may be underdiagnosed, particularly in cases of granulomatosis with polyangiitis or crescentic glomerulonephritis.
\end{abstract}

Keywords: Crescentic glomerulonephritis, Enzyme replacement therapy, Fabry's disease, Granulomatosis with polyangiitis

\section{Background}

Fabry's disease is a rare X-linked, hereditary lysosomal storage disease caused by the deficiency of the enzyme $\alpha$-galactosidase A ( $\alpha \mathrm{GL}-\mathrm{A})$. This deficiency results in the accumulation of the neutral glycosphingolipid globotriaosylceramide (GL-3) in multiple organs [1]. It causes a multisystem condition characterized by reddish-purple maculopapular lesions on the skin (angiokeratoma corporis diffusum), corneal opacities (cornea verticillata) hypohidrosis, gastroenteritis, chronic airflow obstruction, left ventricular hypertrophy, and early-onset of stroke. With advanced age, the progressive lysosomal GL-3 accumulation leads to renal failure due to the dysfunction of interstitial tubules, epithelial cells, and mesangial cells [2]. Therefore, early diagnosis of Fabry's disease is important for successful therapeutic intervention with

\footnotetext{
*Correspondence: hhanaoka@a3.keio.jp

${ }^{1}$ Division of Rheumatology, Department of Internal Medicine, Keio University School of Medicine, 35 Shinanomachi, Shinjuku-ku, Tokyo 160-8582, Japan
} Full list of author information is available at the end of the article enzyme replacement therapy [3]. It's diagnosis is made by demonstrating a deficiency of $\alpha \mathrm{GL}-\mathrm{A}$ in a blood sample or detection of a disease-causing mutation in the GLA gene. Fabry's disease is rare. Its incidence in the United Kingdom is reported to be 0.3 per 100,000 , according to the registry of all cases found between 1980 and 1995 [4,5].

This report describes a rare case of Fabry's disease with granulomatosis with polyangiitis (GPA), which is a multisystem inflammatory disease that affects the respiratory tract and kidneys [6]. The prevalence of GPA has increased in last 2 decades but it is still rare disease [7]. According to United Kingdom general practice research database from 1990 to 2005 , it is reported to be 0.8 per 100,000 [8]. In the present case, upper and lower respiratory tract involvement and pauci-immune necrotizing and crescentic glomerulonephritis were pathologically confirmed. Glucocorticoids and oral cyclophosphamide were administered, followed by enzyme replacement therapy. Literature review found three additional cases of Fabry's disease complicated with crescentic glomerulonephritis 
$[9,10]$. Because both Fabry's disease and crescentic glomerulonephritis are rare diseases, there may be a pathogenic link between these two conditions.

\section{Case presentation}

A 29-year-old man was admitted to our hospital on September 22, 2007 with left maxillary sinus pain and a 1 -month history of general malaise and fever. His past medical history did not disclose any evidence of specific diseases, including renal diseases. So he had not taken any drugs before this admission. Family history revealed that his father died of cerebral hemorrhage at the age of 45 and his mother had no cardiovascular or renal disease. $\mathrm{He}$ has no sibling. At admission, the patient's height was $174 \mathrm{~cm}$, body weight was $79 \mathrm{~kg}$, and his body temperature was $38.2^{\circ} \mathrm{C}$. Left maxillary sinus tenderness was observed on physical examination, but no chest murmur or neurological findings were noted. A panel of laboratory studies revealed the following results: serum creatinine $(\mathrm{Cr}) 0.9 \mathrm{mg} /$ $\mathrm{dl}$, sodium $136.1 \mathrm{mEq} / \mathrm{l}$, potassium $3.9 \mathrm{mEq} / \mathrm{l}$, hemoglobin $15.1 \mathrm{~g} / \mathrm{dl}$, white blood cell count $17,600 / \mu \mathrm{l}$, platelet count $180,000 / \mu \mathrm{l}$, total serum proteins $6.7 \mathrm{~g} / \mathrm{dl}$, albumin $3.1 \mathrm{~g} / \mathrm{dl}$, and C-reactive protein (CRP) $16.5 \mathrm{mg} / \mathrm{dl}$. Although most of these findings are unremarkable, the white blood cell count was marginally high, the albumin level was marginally low, and the CRP level was substantially elevated. Antinuclear antibody or myeloperoxidase-antineutrophil cytoplasmic antibody (ANCA) was not detected, but proteinase 3 (PR3)-ANCA was detected at a low titer (24 enzyme-linked immunosorbant assay unit). Results of negative serum test were obtained for Hepatitis $C$ virus, Hepatitis B surface, and core antigens. HLA-typing was not done. Urinalysis revealed hematuria (51-100 red blood cells per high-power field) and proteinuria (0.58 g/day). Whole body computed tomography (CT) revealed left maxillary sinusitis and multiple lung nodules (Figure 1). Two-dimensional transthoracic echocardiography did not reveal signs of left ventricular hypertrophy, with an interventricular septal thickness of $10 \mathrm{~mm}$ and left ventricular posterior wall thickness of $10 \mathrm{~mm}$. Left ventricular systolic function was preserved (ejection fraction 58.9\%). A CTguided needle biopsy of the lung showed a multinucleated giant cells and inflammatory cell infiltrate in necrotizing lesions (Figure 2a), and a renal biopsy showed focal segmental necrotizing and crescentic glomerulonephritis with interstitial granulomas. We could not find any multinucleated giant cells in renal tissue (Figure $2 \mathrm{~b}-\mathrm{d}$ ). The glomerular podocytes were swollen and vacuolated. A semi-thin

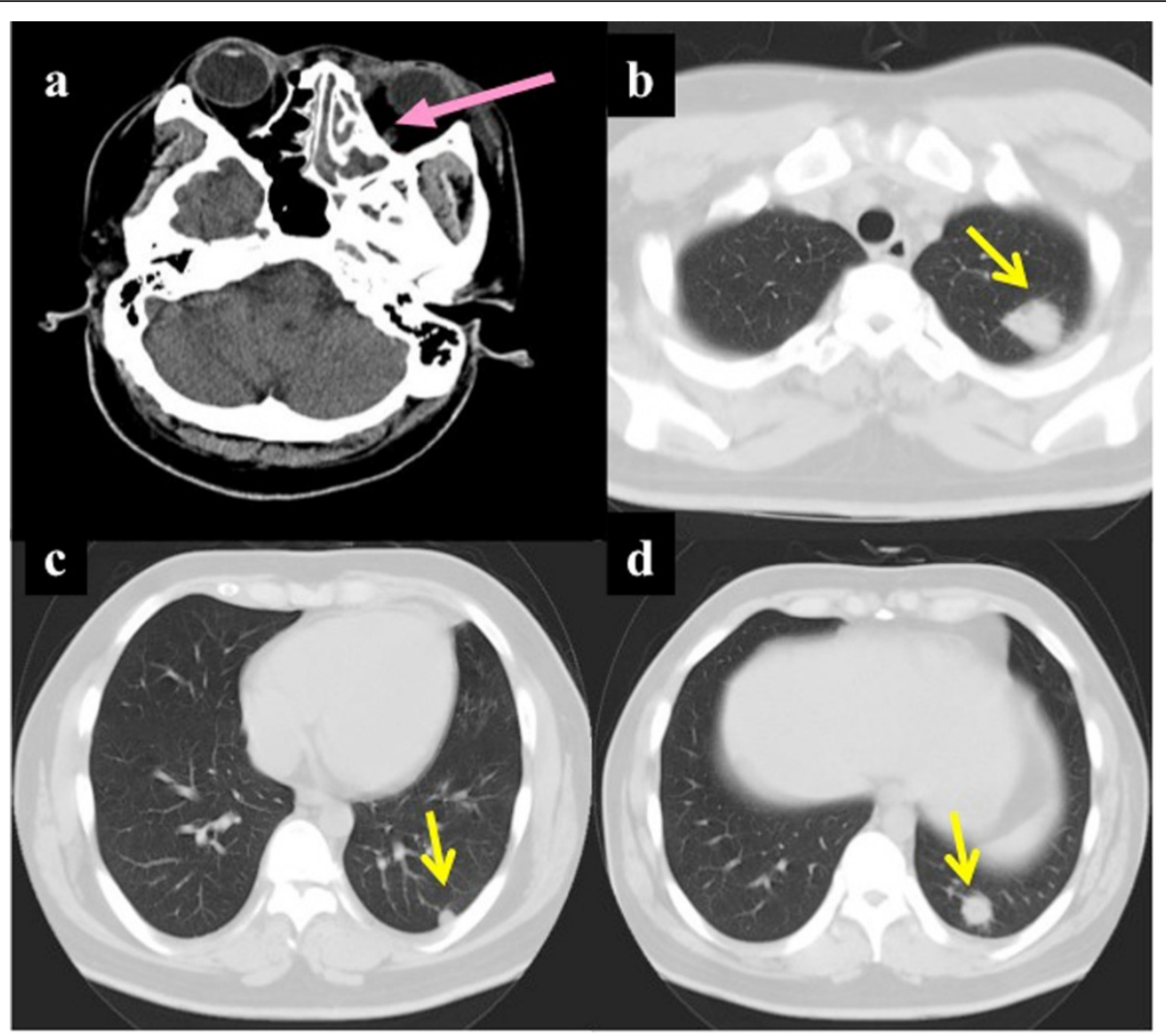

Figure 1 Whole body computed tomography scan before treatment. (a) The left nasal cavity was filled with soft tissue (pink arrow) (b, c, d) Multiple lung nodules were identified (yellow arrows). 


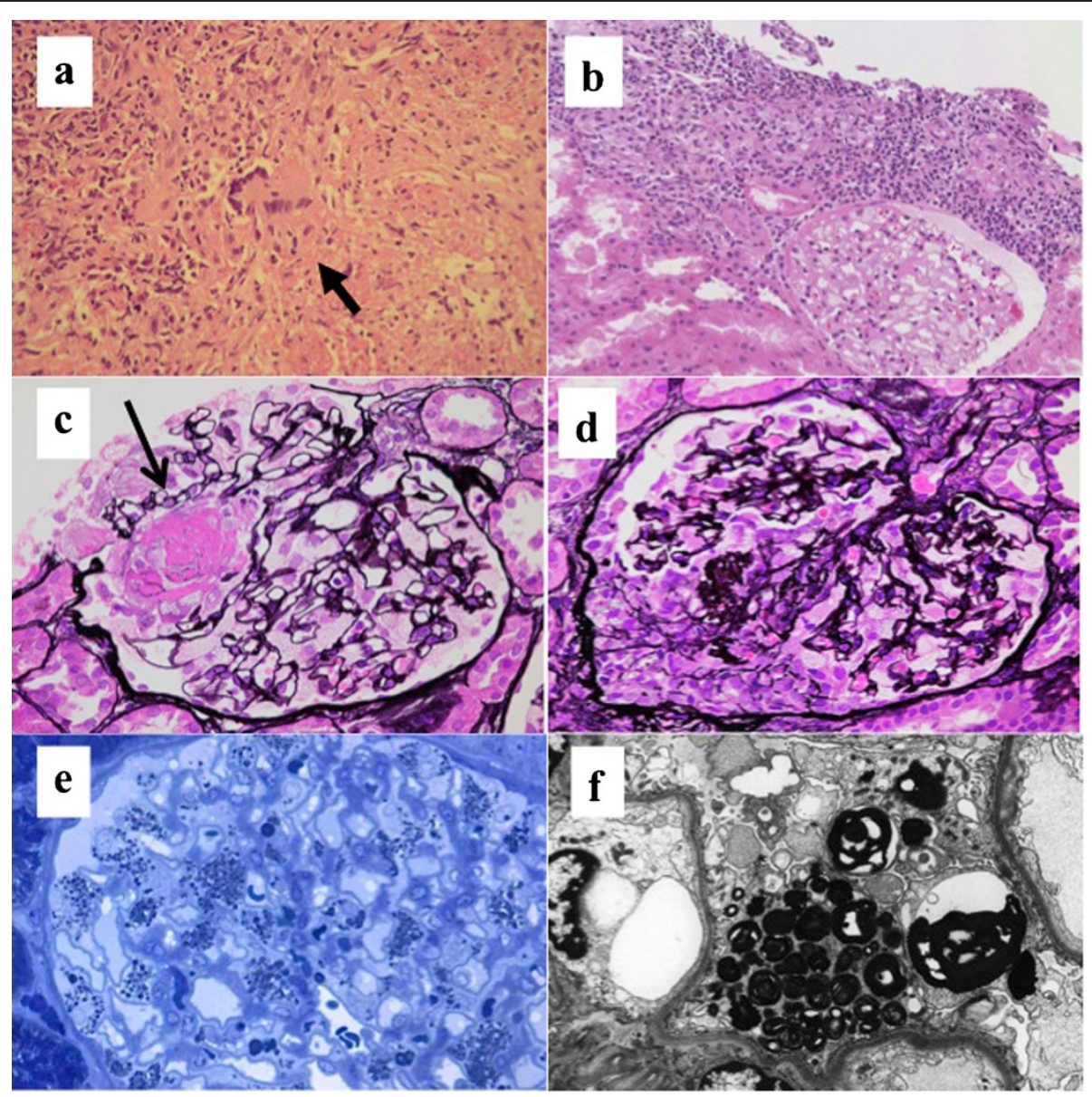

Figure 2 Lung biopsy performed by computed tomography-guided needle biopsy and renal biopsy before treatment. (a) Multi-nucleated giant cells and inflammatory cells infiltrating necrotizing lesions are shown. (b) Granulomatous tubulointerstitial nephritis. Hematoxylin and eosin stain, $\times 40$. (c) Focal segmental necrotizing glomerulonephritis (arrow). The glomerular podocytes were swollen and vacuolated. PASM stain, $\times 400$. (d) Crescentic glomerulonephritis. Podocytes in the cellular crescent were not vacuolated. PASM stain, $\times 400$. (e) Inclusion bodies were detected in the podocytes. Toluidine blue stain, $\times 400$. (f) Podocytes containing osmiophilic inclusion bodies ("myeloid bodies") were revealed by electron microscopy $(\times 2000)$.

section stained with toluidine blue or electron microscopy showed numerous inclusion bodies in the podocytes (Figure 2e). Immunofluorescence revealed no IgG, IgA, IgM, C3, or C1q deposition along the capillary wall. Electron microscopy revealed lamellated inclusion bodies ("myeloid bodies") in the podocytes (Figure 2f). Analysis of the leukocytes demonstrated an $\alpha$ GL-A activity level of $11.8 \mathrm{nmol} / \mathrm{h} / \mathrm{mg}$ (normal range: $49.6-116 \mathrm{nmol} / \mathrm{h} / \mathrm{mg}$ ). After careful consideration of the findings, although this patient lacked any other pathognomonic signs of Fabry's disease, such as acroparesthesias, dyshidrosis, or cutaneous angiokeratomas, a diagnosis of Fabry's disease associated with GPA was made.

Treatment with prednisolone (PSL, $60 \mathrm{mg} /$ day) and oral cyclophosphamide (100 mg/day) was initiated on October 6,2007 . The patient received enzyme replacement therapy in the form of agalsidase alfa at $0.2 \mathrm{mg} / \mathrm{kg}$ every other week starting July 14, 2008. Complete resolution of the proteinuria, lung nodules, and maxillary sinusitis was seen within 2 months of initiation of this therapy. Oral cyclophosphamide was discontinued January 27, 2009, and azathioprine $(50 \mathrm{mg} /$ day) was started for maintenance therapy. The PSL dosage was gradually tapered to $9 \mathrm{mg} /$ day by August 2009. At last follow-up on October 16, 2013, the patient's Cr was $1.3 \mathrm{mg} / \mathrm{dl}$.

\section{Discussion}

This is the first report of the coexistence of Fabry's disease and GPA, although Fabry's disease with necrotizing crescentic glomerulonephritis has been reported in 3 cases previously $[9,10]$. We reviewed the three previous cases and compared their findings with those of the present case (Table 1). Interestingly, none of the previous cases were diagnosed as Fabry's disease before a diagnosis of renal disease was made. Pauci-immune glomerulonephritis was confirmed in the present case and in the two 
Table 1 Demographic and clinical features of patients with Fabry's disease complicated by crescentic glomerulonephritis

\begin{tabular}{|c|c|c|c|c|}
\hline & Singh et al. (5) & Singh et al. (5) & Shimazu et al. (6) & This case \\
\hline Age (years) & 11 & 26 & 58 & 29 \\
\hline Gender & M & $\mathrm{F}$ & $\mathrm{F}$ & M \\
\hline Chief complaint & Fever, arthralgia & Fever, pedal edema & Hematuria, pedal edema & Fever, sinus tenderness \\
\hline BUN (mg/dl) & 35 & ND & 42.3 & 14.4 \\
\hline $\mathrm{Cr}(\mathrm{mg} / \mathrm{dl})$ & 2.6 & 1.4 & 4.7 & 0.9 \\
\hline Proteinuria (g/day) & 1.3 & 0.7 & ND & 0.6 \\
\hline PR3 ANCA & Negative & Negative & Negative & Positive \\
\hline MPO ANCA & Negative & Negative & Negative & Negative \\
\hline Anti-GBM antibody & Negative & Negative & Negative & Negative \\
\hline ANA & Negative & Negative & Negative & Negative \\
\hline Pauci-immune response & Yes & Yes & No & Yes \\
\hline Diagnosis of GPA & No & No & No & Yes \\
\hline aGL-A activity & $<10 \%^{* 1}$ & $50 \%^{*}$ & $76.1^{* *}$ & $11.8^{* * *}$ \\
\hline Mutation in the aGL-A gene & ND & ND & ND & p.N224H/c.670A >C \\
\hline Treatment & PSL IVCY & PSL CYC 150 mg/day & PSL 60 mg/day HD & PSL 60 mg/day CYC 100 mg/day \\
\hline Follow-up period (months) & 16 & 15 & 3 & 72 \\
\hline Final $\mathrm{Cr}$ level (mg/dl) & 8.4 & 1.34 & $2.0-3.0$ & 1.30 \\
\hline
\end{tabular}

${ }^{* 1}$ Percentage of normal mean is shown, ${ }^{* *}$ hetero normal range is $5-100 \mathrm{nmol} / \mathrm{h} / \mathrm{mg},{ }^{* * *}$ normal range is $49.6-116 \mathrm{nmol} / \mathrm{h} / \mathrm{mg}$. ANA, antinuclear antibody, ND: not determined, GPA: granulomatosis with polyangiitis, PSL: prednisolone, IVCY: intravenous cyclophosphamide, CYC: oral cyclophosphamide, HD: hemodialysis, aGL-A: a-galactosidase $A$.

cases reported by Singh, but the remaining patient demonstrated IgG-positive and C3-positive immune deposits along the capillary wall. Serum $\mathrm{Cr}$ was increased in the 3 previous cases $(1.4-4.7 \mathrm{mg} / \mathrm{dl})$ but not in the present case $(0.9 \mathrm{mg} / \mathrm{dl})$, and the amount of proteinuria in the present case was relatively low (0.6-1.3 g/day). Only the present case was serologically positive for PR3-ANCA and definitively diagnosed as GPA. Low peripheral leukocyte $\alpha$ GL-A activity was detected in all three males, but not in the heterozygous female. All four patients were treated with high-dosage prednisolone, and cyclophosphamide was added in three cases. No deaths have been reported and relatively benign courses in short observation periods have been reported. Because renal pathological findings, including the coexistence of granulomatous tubulointerstitial nephritis, were not shown in detail and a survey of the upper and lower respiratory tracts was not done in the three previous cases, the coincidence of subclinical GPA cannot be precisely confirmed.

The pathogenic relationship between Fabry's disease and GPA remains unknown. Galactocerebroside that accumulates in Fabry's disease may be immunogenic [11], leading to the emergence of immune-mediated disease processes. Recently, Lin et al. demonstrated that neutrophil apoptosis in acute lung injury is inhibited via sphingolipid signaling [12]. Neutrophils play the primary pathogenic role in GPA [13-15]. Priming by proinflammatory cytokines causes translocation of ANCA antigens from the lysosomal compartments of neutrophils to the cell surface during the early phase of the inflammatory process. Engagement of ANCA with their antigens on the cell surface and interaction of the Fc part of the antibody with $\mathrm{FC}_{\mathrm{C}}$ receptors activate the neutrophils. Activated neutrophils adhere to vessel walls, produce reactive oxygen radicals, and release lysosomal enzymes, ultimately resulting in necrotizing vascular injury. Accumulated glycosphingolipid may provide long-term survival for neutrophils and contribute to their sustained activation, exacerbating vascular injury.

Recently, a renal variant of Fabry's disease that solely affects kidneys was recognized in hemodialysis patients [16]. Nakao et al. reported that $6(1.2 \%)$ out of 514 hemodialysis patients had low plasma $\alpha$ GL-A activity. This finding suggests that Fabry's disease may be underdiagnosed in general and may occur more often than expected in patients with GPA or crescentic glomerulonephritis. Low $\alpha \mathrm{GL}-\mathrm{A}$ activity may not result from an inherited genetic mutation; it may reflect individual variation in its production or regulation. Further studies will be required to investigate the pathogenic link between the two diseases.

\section{Conclusions}

We describe a case in which Fabry's disease and granulomatosis with polyangiitis occurred together, and discuss three additional cases in which Fabry's disease has been reported to be concomitant crescentic glomerulonephritis. The remarkable concurrence of these disorders in 
this number of cases suggests these two diseases may share a pathogenic link. The information presented in this report suggest that Fabry's disease may, in fact, be underdiagnosed, particularly in cases of GPA or crescentic glomerulonephritis.

\section{Consent}

Written informed consent was obtained from the patient for publication of this Case report. A copy of the written consent is available for review by the Editor of this journal.

\section{Abbreviations}

aGL-A: a-galactosidase A; ANCA: Antineutrophil cytoplasmic antibody; CRP: C-reactive protein; CT: Computed tomography; GL-3: Globotriaosylceramide: GPA: Granulomatosis with polyangiitis; PR3: Proteinase 3; PSL: Prednisolone.

\section{Competing interest}

All authors declare that they have no competing interest.

\section{Authors' contributions}

$\mathrm{HH}$ has collected the clinical data and involved in writing the manuscript. AK made the pathological diagnosis together with KK. TI carried out the genetic studies and evaluated mutation in the aGL-A gene. MK supervised the manuscript. All of the authors have contributed to the preparation of the manuscript. All authors read and approved the final manuscript.

\section{Author details}

'Division of Rheumatology, Department of Internal Medicine, Keio University School of Medicine, 35 Shinanomachi, Shinjuku-ku, Tokyo 160-8582, Japan.

${ }^{2}$ Department of Pathology, Keio University School of Medicine, 35 Shinanomachi, Shinjuku-ku, Tokyo 160-8582, Japan. ${ }^{3}$ Division of Endocrinology, Metabolism and Nephrology, Department of Interna Medicine, Keio University School of Medicine, 35 Shinanomachi, Shinjuku-ku, Tokyo 160-8582, Japan. ${ }^{4}$ Department of Pediatrics, Keio University School of Medicine, 35 Shinanomachi, Shinjuku-ku, Tokyo 160-8582, Japan.

Received: 11 June 2014 Accepted: 23 September 2014

Published: 1 October 2014

\section{References}

1. Brady RO, Gal AE, Bradley RM, Martensson E, Warshaw AL, Laster L: Enzymatic defect in Fabry's disease: ceramidetrihexosidase deficiency. N Engl J Med 1967, 276:1163-1167.

2. Nagano $Y$, Nakashima H, Fukuhara Y, Shimmoto M, Oshima A, Ikari Y, Mori Y, Sakuraba H, Suzuki Y: Hypertrophic cardiomyopathy in late-onset variant of Fabry's disease with high residual activity of alpha-galactosidase A. Clin Genet 1991, 39:233-237.

3. Schiffmann R, Kopp JB, Austin HA 3rd, Sabnis S, Moore DF, Weibel T, Balow $\mathrm{JE}$, Brady RO: Enzyme replacement therapy in Fabry disease: A randomized controlled trial. JAMA 2001, 285:2743-2749.

4. MacDermot KD, Holmes A, Miners AH: Anderson-Fabry disease: clinical manifestations and impact of disease in a cohort of 98 hemizygous males. J Med Genet 2001, 38:750-760.

5. MacDermot KD, Holmes A, Miners AH: Anderson-Fabry disease: clinical manifestations and impact of disease in a cohort of 60 obligate carrier females. J Med Genet 2001, 38:769-775.

6. Hoffman GS, Kerr GS, Leavitt RY, Hallahan CW, Lebovics RS, Travis WD, Rottem M, Fauci AS: Wegener's granulomatosis: analysis of 158 patients. Ann Intern Med 1992, 116:488-498.

7. Ntatsaki E, Watts RA, Scott DG: Epidemiology of ANCA-associated vasculitis. Rheum Dis Clin North Am 2010, 36:447-461.

8. Watts RA, Al-Taiar A, Scott DG, Macgregor AJ: Prevalence and incidence of Wegener's granulomatosis in the UK general practice research database. Arthritis Rheum 2009, 61:1412-1416.

9. Singh HK, Nickeleit V, Kriegsmann J, Harris AA, Jennette JC, Mihatsch MJ: Coexistene of Fabry's disease and necrotizing and crescentic glomerulonephritis. Clin Nephrol 2001, 55:73-79.
10. Shimazu K, Tomiyoshi Y, Aoki S, Sakemi T, Sugihara H: Crescentic glomerulonephritis in a patient with heterozygous Fabry's disease. Nephron 2002, 92:456-458.

11. Hamers NM, Donker-Koopman WE, Coulon-Morelec MJ, Dupouey P, Tager JM: Characterization of antibodies against ceramide trihexoside and globoside. Immunochemistry 1978, 15:353-358.

12. Lin WC, Lin CF, Chen CL, Chen CW, Lin YS: Inhibition of neutrophil apoptosis via sphingolipid signaling in acute lung injury. J Pharmacol Exp Ther 2011, 339:45-53.

13. Jennette JC, Xiao H, Falk RJ: Pathogenesis of vascular inflammation by anti-neutrophil cytoplasmic antibodies. J Am Soc Nephrol 2006, 5:1235-1242.

14. Franssen CF, Stegeman CA, Kallenberg CG, Gans RO, De Jong PE, Hoorntje SJ, Tervaert JW: Antiproteinase 3 and antimyeloperoxidase associated vasculitis. Kidney Int 2000, 57:2195-2206.

15. Van Paassena P, Tervaerta JW, Heeringab P: Mechanisms of vasculitis. how pauci-immune is ANCA-associated renal vasculitis? Nephron Exp Nephrol 2007, 105:10-16.

16. Nakao S, Kodama C, Takenaka T, Tanaka A, Yasumoto Y, Yoshida A, Kanzaki T, Enriquez AL, Eng CM, Tanaka H, Tei C, Desnick RJ: Fabry's disease: Detection of underdiagnosed hemodialysis patients and identification of a "renal variant" phenotype. Kidney Int 2003, 64:801-807.

doi:10.1186/1471-2369-15-157

Cite this article as: Hanaoka et al:: A rare association between Fabry's disease and granulomatosis with polyangiitis: a potential pathogenic link. BMC Nephrology 2014 15:157.

\section{Submit your next manuscript to BioMed Central and take full advantage of:}

- Convenient online submission

- Thorough peer review

- No space constraints or color figure charges

- Immediate publication on acceptance

- Inclusion in PubMed, CAS, Scopus and Google Scholar

- Research which is freely available for redistribution 